\title{
PROSEDUR PENURUNAN FREE FALL LIFEBOAT DENGAN MENGGUNAKAN DAVIT GUNA MENGURANGI RESIKO KECELAKAAN PADA SAAT LATIHAN ABANDON SHIP DRILL DI MV. GEOPARK VENUS
}

\author{
Samsul Huda ${ }^{a}$, Slamet Riyadi ${ }^{\mathrm{b}}$, Prastiyo Jaya Kumara ${ }^{\mathrm{c}}$ \\ a dan b Dosen Program Studi Nautika PIP Semarang \\ ${ }^{c}$ Alumni PIP Semarang \\ *email : samhud72@yahoo.com
}

\begin{abstract}
ABSTRAK
Supaya pelayaran dapat berjalan dengan aman, diperlukan free fall lifeboat yang dapat beroperasi dengan normal. Salah satu indikator free fall lifeboat dalam keadaan normal dapat dilihat dari kondisi fisik dan fungsinya. Dan untuk mencapai pelaksaan latihan penurunan free fall lifeboat dalam keadaan aman dibutuhkan pemahaman dasar setiap crew kapal tentang prosedur penurunan free fall lifeboat, serta tugas masing-masing crew selain itu latihan penurunan free fall lifeboat harus dilaksanakan secara terjadwal sesuai dengan ketetapan masingmasing perusahaan perkapalan. Ada 4 tahapan prosedur penurunan free fall lifeboat yaitu planning, Organizing, Actuating dan Controling.

Dari proses tersebut dapat ditarik kesimpulan kegagalan dalam pelaksanaan latihan penurunan free fall lifeboat dikarenakan ketidakpahaman seorang crew kapal terhadap prosedur penurunan freefall lifeboat dan seorang crew harus memahami tugas dan tanggung jawab dalam suatu kegiatan sesuai dengan muster list.
\end{abstract}

\section{Kata kunci: Lifeboat, Keadaan Darurat, Lowering, free fall lifeboat, Davit}

\section{PENDAHULUAN}

Di dalam SOLAS Bab III menetapkan bahwa kapal yang dibangun setelah bulan Juli tahun 1986 diharuskan menggunakan lifeboat tertutup, meskipun sebagian kapal penumpang tidak menggunakan jenis lifeboat seperti ini. Kapal yang dibangun sebelum bulan Juli tahun 1986 boleh menggunakan lifeboat terbuka.

MV. Geopark Venus merupakan kapal yang dibangun pada bulan Agustus tahun 2013. Kapal ini murupakan kapal curah yang memiliki panjang 139,81 meter dan lebar 25,00 meter. Sehingga kapal ini diwajibkan menggunakan jenis lifeboat tertutup (enclosed lifeboat). Jenis lifeboat yang berada di kapal MV. Geopark Venus merupakan jenis free fall lifeboat, dimana free fall lifeboat ini berada di daerah buritan kapal.

Agar pelayaran dapat berjalan dengan aman, diperlukan free fall lifeboat yang beroperasi dengan normal. Salah satu indikator free fall lifeboat dalam keadaan normal dapat dilihat dari kondisi fisik dan fungsinya, yang ditandai dengan kelancaran pada saat pengoperasian penurunan free fall lifeboat tanpa adanya hambatan-hambatan, mulai dari melepas lashing line sampai free fall life boat terjun di atas air laut. Sehingga resiko kecelakaan dapat ditekan sekecil mungkin.

Untuk mencapai pelaksaan latihan penurunan free fall lifeboat dalam keadaan aman dibutuhkan pemahaman dasar setiap crew kapal tentang prosedur penurunan free fall lifeboat dan untuk tugas masing-masing crew selain itu latihan penurunan free fall lifeboat harus dilaksanakan secara terjadwal sesuai dengan ketetapan masing-masing perusahaan perkapalan.

Besarnya resiko kecelakaan yang terjadi dalam latihan penurunan free fall lifeboat selama penulis melaksanakan praktek laut di kapal MV. Geopark Venus. Segala kegiatan pada kapal ini sehari-hari selalu melibatkan kegiatan fisik dan konsentrasi 
juga kemampuan, keahlian dari individu untuk dapat dengan segera menyelesaikan tugas dengan cepat tetapi aman bagi orangorang yang ikut terlibat.

Penelitian yang diambil yaitu "Prosedur penurunan free fall lifeboat dengan menggunakan davit guna mengurangi resiko kecelakaan pada saat latihan abandon ship drill di MV. Geopark Venus".

\section{METODE PENELITIAN}

Metode penelitian yang digunakan oleh peneliti dalam penyampaian masalah adalah metode deskriptif kualitatif, untuk menggambarkan dan menguraikan objek yang diteliti.

\section{Metode Deskriptif}

Menurut Rully Indrawan, M.A (2014:156), mendefinisikan deskriptif adalah mengembangkan detail penting dari hasil analisis data dari berbagai sumber untuk membangun potret individu atau peristiwa. Deskriptif harus mampu membawa pembaca laporan penelitian kearah peristiwa yang dialami, dan sekaligus mengajak memahami pribadi seseorang, peristiwa atau kebiasaan suatu komunitas yang tengah diamati. Penelitian ini selain mengandung hal-hal yang bersifat teori juga memuat hal-hal yang bersifat praktikum. Dalam pengertian bahwa selain ditulis dari beberapa literatur buku, juga bersumber dari obyek-obyek penelitian yang terdapat dalam buku. Penggunaan aspek visual observasi sangat berperan dalam penelitian buku ini. Oleh karena itu penelitian ini memuat tentang sebuah penelitian yang dimunculkan dalam jenis-jenis permasalahan yang akan diteliti. Dalam penelitian ini digunakan metode penelitian secara deskriptif. Adapun pengertian lain dari deskriptif adalah tulisan yang berisi pemaparan, uraian dan penjelasan tentang suatu objek sebagaimana adanya pada waktu tertentu dan mengambil kesimpulan atau keputusan secara umum.

2. Metode Kualitatif

Menurut Tohirin (2013:02), mendefinisikan metode kualitatif adalah penelitian yang menggunakan pendekatan naturalistik untuk mencari dan menemukan pengertian atau pemahaman tentang fenomena dalam suatu layar yang khusus. Metode kualitatif ini digunakan karena beberapa pertimbangan.

a. Menyesuaikan metode kualitatif lebih mudah apabila berhadapan dengan kenyataan jamak.

b. Metode ini menyajikan secara langsung hakikat hubungan antara peneliti dan responden.

c. Metode ini lebih peka dan lebih dapat menyesuaikan diri dengan banyak penajaman pengaruh bersama terhadap pola-pola nilai yang dihadapi.

Pengumpulan data dengan mencari sumber dalam berbagai buku mengenai keterangan-keterangan yang dibahas dalam penelitian. Begitu juga dengan penelitian, selain melaksanakan riset lapangan juga melaksanakan riset kepustakaan guna mendapatkan keterangan yang akurat mengenai masalah yang akan dibahas. Riset penelitian itu peneliti laksanakan dengan jalan mengumpulkan buku-buku yang berkenaan dengan penurunan free fall lifeboat sewaktu praktek di atas kapal dan yang ada di dalam perpustakaan PIP / BPLP Semarang.

\section{PEMBAHASAN}

Prosedur penurunan dengan mengggunakan davit adalah suatu prosedur menurunkan dengan menggunakan bantuan davit yang dihubungkan menggunakan sling yang terdapat pada free fall lifeboat yang kemudian di kaitkan dengan menggunakan hook pada davit kapal itu sendiri.

Di dalam kegiatan penurunan merupakan kegiatan yang sangat bahaya karena mempunyai tingkat resiko kecelakaan yang tinggi. Oleh karena itu dibutuhkan prosedur pelaksanaan yang benar. Dalam prosedur pelaksanaan terdiri dari empat tahap yaitu.

\section{a. Planning}

Pada tahap ini seorang master dan officer merencanakan akan diadakannya pelaksanaan penurunan dengan memperhatikan faktor-faktor yang menunjang tercapainya pelaksanaan sesuai dengan SOLAS. Adapun faktor-faktor tersebut meliputi: 
Samsul Huda a, Slamet Riyadi ${ }^{\mathrm{b}}$, Prastiyo Jaya Kumara ${ }^{\mathrm{c}}$

1. Faktor luar

Cuaca

a) Kesiapan crew

Kesiapan crew merupakan faktor terpenting dalam pelaksanaan latihan penurunan free fall lifeboat. Crew kapal dikatakan siap ketika keadaan crew dalam keadaan sehat tanpa ada kelelahan dari akibat kegiatan lain. Maka untuk mengetahui crew siap untuk melakukan kegiatan pelatihan penurunan free fall lifeboat, sebagai officer kita harus menanyakan secara langsung apakah crew dalam keadaan sehat dan tidak mengalami kelelahan. Apabila ada salah satu crew kapal dalam keadaan sakit, maka crew tersebut tidak dianjurkan untuk mengikuti kegiatan latihan ini. Karena dikhawatirkan akan menimbulkan resiko kecelakaan yang tinggi.

b) Kondisi lingkungan sekitar

Apabila kita akan melaksanakan latihan penurunan free fall lifeboat, nahkoda harus mengamati kondisi lingkungan. Apakah kondisi lingkungan memperbolehkan melakukan latinan penurunan free fall lifeboat atau kebalikannya. Kondisi lingkungan dikatakan memperbolehkan melakukan latihan penurunan free fall lifeboat sebagai berikut:
1) Alur pelayaran sepi (tidak ramai);
2) Diijinkan oleh pelabuhan setempat atau pihak yang mempunyai wewenang;
3) Kedalaman air laut mencukupi untuk dilakukannya latihan penurunan;
4) Bebas dari binatang buas.

\section{Faktor dalam}

a) Kesiapan peralatan

Peralatan penurunan free fall
lifeboat merupakan merupakan
pengaruh penting dimana fartor ini
merupakan obyek dalam

pelaksanaan penurunan free fall lifeboat. Adapun faktor-faktor peralatan meliputi:

1) Kesiapan free fall lifeboat

2) Kesiapan davit

3) Kesiapan winch

b) Draft kapal

Draft kapal dapat dikatakan mendukung diadakannya latihan penurunan free fall lifeboat apabila draft kapal dalam keadaan besar hal ini terjadi pada saat kapal terdapat muatan penuh. Sehingga jarak antara posisi free fall lifeboat dengan permukaan kecil sehingga memudahkan dalam proses penurunan. Apabila draft kapal kecil maka akan belaku sebaliknya.

b. Organizing

Pada tahap ini seorang master dan chief officer memegang peranan penting, karena pada tahap organizing akan diadakan pembagian tugas kepada seluruh crew dari jabatan mester sampai jabatan cadet. Pada tahap ini merupakan penetu bagaimana prosedur penurunan free fall lifeboat akan dilakukan. Dan pada tahap ini merupakan penentu bagaimana jalan cerita suatu kegiatan penurunan free fall lifeboat. adapun tugas-tugas masing-masing crew sesuai master list.

c. Actuating

Pelaksanaan free fall lifeboat dikatakan berhasil jika pelaksanaan pada tahap ini dikatakan berhasil sesuai target yang diinginkan. Hal ini dikaranakan pada tahap ini merupakan pelaksanaan dan tujuan akhir dari tujuan latihan drill abandon ship dengan menggunakan davit. Maka dari itu pada tahap actuating harus dilakukan sesuai dengan pentunjuk penggunaan yang dijelaskan dalam manual book yang berjudul "Louching Free Fall Lifeboat With Davit". Adapun urutan dalam pelaksanaan penurunan free fall lifeboat menggunakan davit adalah sebagai berikut: 
1) Membuka lashing line

Pada tahap ini salah satu crew yang bertugas sesuai denga muster list tampil kedepan dan melaksanakan perintah untuk membuka lashing line yang berada diantara pintu masuk free fall lifeboat dengan embarkation station.

2) Cara membuka lashing line

Pada tahap pembukaan lashing line dibutuhkan cara yang benar yaitu lashing line dikendurkan dengan cara diputar bagian ulir diputar ke kiri atau berlawanan dengan arah jarum jam setelah itu, ujung pangkal lashing line ditekan sehingga ujung lain yang terdapat cincin yang mengunci menipis dan cincin tersebut dapat dengan mudah dilepaskan, disaat itu pula penghubung antara wire di sisi kanan dan sisi kiri juga terlepas. Setelah terlepas lashing line ditata secara rapi ditepi dari embarkation station. Hal ini dilakukan agar lashing line tidak menjadi hambatan pada saat penurunan free fall lifeboat.

3) Menarik lashing suport(tali nilon)

Penarikan lahing suport dilakukan setelah lashing line terlepas. Lashing line terletak di sisi kanan dan kiri dari free fall lifeboat. lashing support ini terbuat dari tali nilon. Dimana tali ini menghubungkan dengan lasing plate. Apabila lashing support ini ditarik secara kencang maka secara otomatis lashinging plate akan membuka sehingga rintangan atau hambatan dalam proses penurunan free fall lifeboat sudah bebas dan free fall lifeboat akan aman pada saat peluncuran.

4) Bosun stand by untuk pengoperasian panel

Setelah free fall lifeboat sudah terbebas dari segala hambatan. Bosun sudah harus sudah berada diposisi sebagai pengoperasi panel. Panel ini berfungsi sebagai alat untuk mengendalikan davit dimana panel ini terhubung dengan winch sebagai tenaga penggerak. Di dalam panel terdapat dua buah joy stick dimana stick yang pertama berfungsi sebagai pengendali winch yang menggerakkan davit dan satunya lagi berfungsi sebagai pengendali winch yang menggerakkan wire davit.

5) Melepas hook dari lashing

Dengan mengguanakan joy stick yang terhubung dengan winch yang menggerakkan wire. Crew yang bertugas memasang hook dari free fall lifeboat harus segara melepaskannya dengan cekatan dan hati-hati melepaskan hook dengan lashingannya. Lashing hook ini terdapat dua buah yang berada di antara free fall lifeboat dengan embarkation station.

6) Memasang hook ke sling yang ada di samping kanan kiri lifeboat

Free fall lifeboat adalah pertama kali hook dilepaskan dengan lashing-annya kemudian sling sebagai penghubung free fall lifeboat dengan hook yang terletak di sisi kanan dan sisi kiri ini diambil kemudian dipasangkan dengan hook yang sudah terlepas. Dalam pemasangan ini harus dilakukan dengan dua orang crew karena pemasangan tersebut membutuhkan tenaga yang besar.

7) Ikatkan tali painter ke samping kanan dan kiri lifeboat di daerah belakang

Setelah free fall lifeboat sudah terhubung dengan davit maka langkah selanjutnya adalah pemasangan tali painter. Tali painter yang digunakan sekurang-kurangnya memiliki panjang 200 meter. Tali ini biasanya sudah berada dalam lifeboat karena tali painter ini merupakan inventaris yang harus di lengkapi di dalam free fall lifeboat. Cara mengikat tali painter dengan free fall lifeboat yaitu kita ambil dua buah tali painter yang sudah tersedia kemudian kita ikatkan di sisi kanan dan sisi kiri di bagian belakang free fall lifeboat.

8) Atur kondisi tali painter agar tidak dalam kondisi terlilit

Maka crew yang bertugas memegang tali painter menata posisi tali painter di atas reling dengan tujuan agar tali painter tidak menjadi hambatan pada 
Samsul Huda a, Slamet Riyadi ${ }^{\mathrm{b}}$, Prastiyo Jaya Kumara ${ }^{\mathrm{c}}$

saat proses penurunan free fall lifeboat. Selain itu tujuan dalam penataan tali agar tali tersusun rapi untuk mencegah terbelitnya kaki salah satu crew yang bertugas di posisi itu, sehingga resiko bahaya dapat terhindari.

9) Ulurkan ujung tali painter ke poop deck dan ada crew yang bertugas untuk memegangnya

Setelah tali tertata rapi di bagian B deck (embarkation station) maka tali diulurkan ke daerah poop deck dan di tangkap oleh crew pemegang tali painter yang bertugas di daerah poop deck yang kemudian ditata dengan rapi, hal ini bertujuan agar tidak terjadinya seorang crew yang sedang melakukan tugas tersangkut oleh tali, yang mengakibatkan crew terjatuh atau terpeleset karena pada daerah ini merupakan daerah yang sering digunakan tempat lewatnya crew dalam melaksanakan tugasnya.

10) Sebagian crew masuk dalam lifeboat dan terakir operator memastikan kondisi aman

Setelah tali painter sudah tertata rapi, sebagian crew yang bertugas dalam pengoperasian lifeboat masuk kedalam dengan hati-hati. Karena pada saat masuk free fall lifeboat posisi lifeboat ini dalam keadaan miring dan bahan dari free fall lifeboat merupakan fiberglass dimana bahan ini bersifat licin, sehingga diperlukan langkah perlahan dan hati-hati, hal ini bertujuan agar crew yang masuk ke dalam free fall lifeboat tidak terpeleset. Dan untuk operator harus masuk paling belakang karena operatorlah yang bertugas untuk menutup pintu free fall lifeboat.

11) Seluruh crew memasang safety belt dan menyesuaikan posisi senyaman mungkin

Setelah crew yang bertugas di dalam free fall lifeboat sudah masuk. Crew yang bertugas didalam lifeboat harus duduk sesuai dengan kursi yang sudah di tetapkan yang bisa dilihat di kartu posisi duduk yang berada di dinding bagian dalam free fall lifeboat. Tidak hanya itu bagi crew yang bertugas harus memakai safety belt dengan kencang dan senyaman mungkin.

12) Operator menggoyangkan handle yang ada di bawah kursi secukupnya (agar main lashing terlepas)

Setelah posisi duduk crew sudah benar maka seorang operator free fall lifeboat memulai untuk melepaskan main lashing dengan cara memompa handle yang berada di samping kiri kursi operator. Jumlah pemompaan sekitar 710 pompaan dan apabila main lashing belum terlepas maka sang operator harus membuka main lashing secara manual (emergency release). Posisi emergency release berada di belakang didekat kursi yang paling belakang, cara menggunakan emergency release adalah memutar dengan arah berlawanan jarum jam.

13) Main lashing sudah terlepas

Setelah release system sudah dioperasikan secara otomatis main lashing terbuka. Hal ini dikarenakan handle yang telah di pompa menekan udara di pipa yang menghubungkan ke system release main lashing sehingga secara otomatis pin membuka dengan sendirinya. Kemudian segel yang berfungsi me-lashing antara free fall lifeboat dengan deck B ditempatkan pada posisi yang aman sehingga tidak menjadi hambatan dalam proses penurunan.

14) Operator menurunkan lifeboat dengan mengoperasikan panel sesuai dengan aba-aba chief officer

Setelah main lashing terlepas pengoperasi panel harus segera mengoperasikan panel sesuai dengan perintah chief officer. Di tahap ini operator harus senantiasa memperhatikan keadaan free fall lifeboat dan davit. Dikarenakan pada tahap ini memiliki resiko sangat besar tentang bersinggungannya free fall lifeboat dengan davit. Persinggungan ini akan menyebabkan kerusakan pada 
lambung luar free fall lifeboat dan tidak hanya itu persinggungan ini juga akan mengakibatkan kerusakan pada tiang davit yang berada di samping free fall lifeboat saat diturunkan.

15) Pemegang tali menggontrol free fall lifeboat agar free fall lifeboat tidak bergoyang akibat pengaruh dari gelombang air laut

Pada saat free fall lifeboat diturunkan maka seorang crew yang bertugas pemegang tali harus siap dalam posisinya dan memegang tali dengan erat. Pada saat ini kekuatan memegang tali antara sisi kanan dan sisi kiri harus seimbang. Hal hal ini bertujuan untuk mengurangi goyangan yang ditimbulkan dari akibat gelombang air laut di sekitar kapal, yang menyebabkan terbenturnya dinding luar free fall lifeboat dengan lengan davit.

16) Pada saat free fall lifeboat di daerah bawah tugas pemegang tali di serahkan pada tim tali bagian bawah

Pada saat posisi free fall lifeboat sudah sejajar dengan poop deck maka tugas pemegang tali diserahkan ke crew yang bertugas di area poop deck. Hal ini bertujuan agar pengontrolan kondisi free fall lifeboat lebih mudah. Karena pada saat kondisi free fall lifeboat sejajar dengan poop deck pandangan crew yang berada di embarkation station sangatlah kurang. Maka dari itu tugas pemegang tali diserahkan ke area poop deck. Pada proses penyerahan tali harus hati-hati dan jangan sampai tali terbelit akibat kesalahan pengambilan tali yang kurang benar.

17) Free fall lifeboat sampai di permukaan air dan wire davit masih dalam keadaan kencang dan pada saat ini mesin free fall lifeboat dihidupkan.

Pada saat free fall lifeboat sudah berada di permukaan air laut maka seorang operator harus menjaga tali tetap kencang. Hal ini bertujuan supaya free fall lifeboat mempunyai goyangan atau olingan yang terbatas sehingga memudahkan crew yang melepaskan tali painter untuk melepaskannya. Pada saat ini tali painter harus segera dikendurkan hal ini bertujuan untuk memermudah proses pelepasan tali. Karena tali pada saat kendur lebih mudah dilepaskan dari pada saat tali dalam keadaan kencang. Dan tidak hanya itu pada tahap ini mesin free fall lifeboat harus segera dihidupkan. Dikarenakan apabila wire davit sudah terlepas semua dan ternyata free fall lifeboat tidak bisa dihidupkan, pada saat pemasangan kembali dalam rangka pengangkatan kembali free fall lifeboat pada posisinya akan sulit dilakukan.

18) Tali painter dilepas dari free fall lifeboat

Pada saat tali painter sudah kendur maka dangan segera crew yang berada di free fall lifeboat keluar dengan hatihati melewati pintu. Pada saat ini petugas pelepas tali painter harus sangat hati-hati. Dikarenakan dari permukaan free fall life boat yang licin dan goncangan free fall lifeboat yang disebabkan oleh gelombang air laut. Apabila tidak hati-hati maka akan menimbulkan resiko orang jatuh kelaut. Maka dari itu untuk lebih aman crew yang bertugas harus selalu memakai life jacket.

19) Wire davit diturunkan agar kendur supaya hook mudah dilepaskan dari sling bagian kanan dan kiri free fall lifeboat

Setelah tali painter terlepas maka bosun harus segera menurunkan wire davit. Hal ini dilakukan supaya hook turun kebawah dan sling dalam keadaan kendur sehingga memudahkan dalam proses penurunan. Pada saat seperti ini crew yang bertugas melepaskan hook dengan sling harus hati-hati dan selalu memperhatikan block. Karena sangat beresiko ketika block tersebut oleng dan membentur kepala crew yang bertugas, oleh karena itu crew harus memakai safety helm pada saat pengoperasian kegiatan penurunan free fall lifeboat. 
Prosedur Penurunan Free Fall Lifeboat dengan Menggunakan Davit Guna Mengurangi Resiko Kecelakaan pada Saat Latihan Abandon Ship Drill di MV. Geopark Venus

Samsul Huda a, Slamet Riyadi ${ }^{\text {b }}$, Prastiyo Jaya Kumara ${ }^{\mathrm{c}}$

20) Hook sudah terlepas dan free fall lifeboat siap untuk melakukan manouver

Sesudah hook terlepas maka crew yang bertugas di dalam free fall lifeboat harus dengan segera masuk kedalam free fall lifeboat. sebelum free fall lifeboat akan dijalankan manouver. Agar mencegah terjadinya terjatuhnya crew yang bertugas ke permukaan air laut saat pelaksanaan maneuver di permukaan air laut.

\section{KESIMPULAN}

Berdasarkan hasil pengamatan dan analisis data yang telah dilakukan di atas kapal MV. Geopar Venus tentang Prosedur Penurunan Free Fall Lifeboat dengan Menggunakan Davit Pada Saat Latihan Abandon Ship Drill dapat disimpulkan sebagai berikut :

1. Dalam proses penurunan free fall lifeboat dengan menggunakan davit diperlukan konsentrasi yang baik dan dalam proses pelaksanaan kegiatan latihan ini diperlukan beberapa tahap yaitu meliputi Planning, Organizing, Actuating dan Controlling.

2. Peranan crew dalam latihan penurunan free fall lifeboat harus sesuai dengan muster list dan seluruh crew kapal harus mengerti tugas masing-masing dan mengerti tetang hal apa saja yang boleh dilakukan dan larangan-larangan yang dilakukan saat pelaksanaan.

\section{DAFTAR PUSTAKA}

Hariwijaya, M dan Triton. 2011. Pedoman Penulisan Penelitian dan Tesis. Yogyakarta: Oryza

Indrawan, Rully dan Yuniawati Poppy. 2014. Metodologi Penelitian. Bandung: Refika Aditama

Lorne dan Maclean. 2001. self teach series survival techniques. Cardigan Street: Cardigan House
Purwantomo, Agus Hadi. 2004. Emergency Procedure \& SAR. Politeknik Ilmu Pelayaran Semarang . 2006. Crowd Safety Management in Crisis Situation. Politeknik Ilmu Pelayaran Semarang . 2002. Crisis Management and Human Behavior. Politeknik Ilmu Pelayaran Semarang

SOLAS. 2003. I.C Brindle \& Co

Syatori, Nasehudin Toto dan Gozali Nanang. 2012. Metode Penelitian Kuantitatif. Bandung: Setia Pustaka

Tohirin. 2012. Metode Penelitian Kualitatif. Jakarta: Rajagrafindo Persada

Wright, C.H. 1997. Survival at Sea the Lifeboat and Liferaft. Liverpol: the James Laver Printing Co. Ltd 